\title{
HIPERPARATIREOIDISMO NUTRICIONAL SECUNDÁRIO EM EQUINOS E RUMINANTES: REVISÃO DE LITERATURA
}

\author{
QUEIROZ, Daniela Junqueira de ${ }^{1}$ \\ BERNARDI, Nara Saraiva ${ }^{1}$ \\ DIAS, Deborah Penteado Martins ${ }^{1}$ \\ CADIOLI, Fabiano Antonio ${ }^{2}$
}

\begin{abstract}
RESUMO: O hiperparatireoidismo nutricional secundário é um distúrbio metabólico que acomete principalmente equídeos, mas pode se manifestar em caprinos e suínos. A etiologia está relacionada a alterações nas concentrações séricas de cálcio e fósforo devido à ingestão desbalanceada na dieta, levando a hipersecreção do paratormônio e consequente hiperparatireoidismo, que se manifesta por osteodistrofia fibrosa. A apresentação clássica é o aumento de volume, em geral bilateral e simétrico, dos ossos do crânio, sendo que o diagnóstico baseia-se principalmente na presença desta alteração. Entretanto, outros ossos também podem ser acometidos. Testes bioquímicos podem contribuir para o diagnóstico ao revelarem concentrações séricas de cálcio ionizado abaixo dos valores de referência e teor sérico de fósforo orgânico acima do normal, além de aumento na atividade da enzima fosfatase alcalina. Exames radiográficos demonstram opacidade óssea diminuída. O tratamento consiste principalmente na correção do desequilíbrio cálcio:fósforo na dieta e a profilaxia é de extrema importância a fim de se evitar prejuízos econômicos.
\end{abstract}

Palavras-chave: Osteodistrofia fibrosa. Cálcio. Fósforo.

\section{NUTRITIONAL SECONDARY HYPERPARATHYROIDISM IN HORSES AND RUMINANTS: A REVIEW}

\begin{abstract}
SUMMARY : Nutritional secondary hyperparathyroidism is a metabolic disorder that commonly affects horses, but can also manifest in goats and pigs. The etiology is related to changes in serum calcium and phosphorus due to dietary imbalance, leading to hypersecretion of parathyroid hormone, and consequent hyperparathyroidism manifested by fibrous osteodystrophy. The classic clinical presentation is swelling of the bones of the skull, usually bilateral and symmetrical, and diagnosis could be determined on the presence of such change. However, other bones may also be affected. Biochemical laboratory tests may contribute to the diagnosis, showing low levels of ionized calcium, high levels of organic phosphorus, and increased activity of alkaline phosphatase. Radiographic examination usually reveals decreased bone opacity. Treatment mainly consists in correcting the calcium:phosphorus imbalance in the diet, and prophylaxis is important in order to avoid financial losses.
\end{abstract}

Keywords: Fibrous osteodystrophy. Calcium. Phosphorus.

\section{INTRODUÇÃO}

Desde a antiguidade o cavalo é utilizado pelo homem para diversas funções, como meio de transporte, instrumento de guerra e, principalmente nos dias de hoje, para o lazer e o esporte, sendo responsável por uma movimentação financeira expressiva (HINCHCLIFF; GEOR, 2004). Neste contexto a preocupação com a saúde e a nutrição dos equídeos vem aumentando

\footnotetext{
${ }^{1}$ FCAV/ UNESP - Campus de Jaboticabal

${ }^{2}$ FMV/UNESP - Campus de Araçatuba
} 
consideravelmente na tentativa de se aumentar o desempenho e a vida útil desses animais, além de diminuir os gastos com diagnóstico e tratamento de enfermidades (CURCIO et al., 2010).

O hiperparatireoidismo nutricional secundário (HNS), também conhecido popularmente como "doença da cara inchada", é um distúrbio metabólico que acomete principalmente equídeos, mas também caprinos e suínos (ASLANI et al., 2001; RADOSTITS et al., 2002; CURCIO et al., 2010). Em bovinos a doença já foi induzida experimentalmente por meio do fornecimento de alimentação desbalanceada em relação aos níveis de cálcio e fósforo (LEITE et al., 2004).

O HNS é responsável por prejuízos econômicos relacionados não só aos gastos com diagnóstico e tratamento, mas também à diminuição do desempenho, especialmente ao acometer equinos atletas, e à diminuição da produção de carne e leite, ao acometer caprinos. A dificuldade de mastigação e deglutição com consequente diminuição do consumo de alimentos e perda de peso são as principais responsáveis pela diminuição na produção. Cruz et al. (2002), ao relatarem um caso de HNS em caprinos, sugeriram que a diminuição do consumo de alimentos pelas cabras devido à dificuldade de ingestão pudesse conduzi-las a uma situação de enorme desconforto, sendo inclusive responsável pelo aumento da incidência de abortos.

\section{ETIOLOGIA}

O HNS está relacionado a um desbalanço nas concentrações séricas de cálcio e fósforo que, segundo Swartzman et al. (1978), devem estar na proporção em torno de 2:1 em equinos, variando discretamente entre as diferentes categorias animais. Em cavalos de manutenção a relação de cálcio e fósforo deve ser de 1,4:1, enquanto em animais em crescimento deve estar em torno 1,8:1 e em éguas lactantes 1,9:1. Relações abaixo de 1:1, nas quais a concentração de fósforo excede a de cálcio, podem prejudicar a absorção de cálcio (NUTRIENT..., 1989). Dietas contendo concentrações de cálcio adequadas, porém com excesso de fósforo, são responsáveis pelo aumento generalizado da reabsorção de cálcio dos ossos, a fim de se manter a relação fisiológica normal (2:1) no sangue, e consequente substituição por tecido fibroso. Alimentação composta basicamente por cereais, como o milho, e seus subprodutos, é importante na etiologia uma vez que esses elementos são pobres em cálcio (SWARTZMAN et al., 1978).

Os equinos são herbívoros não ruminantes capazes de suprir quase integralmente sua demanda nutricional por meio do consumo de gramíneas, uma vez que apresentam o trato digestório adaptado à digestão e utilização de dietas com altos níveis de fibra (BRANDI; FURTADO, 2009; CURCIO et al., 2010), tendo como principal fonte de alimentação as forragens. Existem alguns compostos presentes nas pastagens que indisponibilizam a utilização de determinados nutrientes (PAGAN, 1998). Dentre eles o oxalato apresenta grande importância 
uma vez que está presente em uma grande variedade de pastagens tropicais, dentre elas Setaria anceps, Cenchurus ciliaris, Panicum maximum, Pennisetum clandestinum e Brachiaria spp. (MÉNDEZ; RIET-CORREA, 2007). O oxalato é uma substância que ao ser absorvida pelo organismo se une ao cálcio formando um composto estável chamado oxalato de cálcio, e indisponibilizando o aproveitamento deste mineral pelo organismo (PUOLI-FILHO et al., 1999; MIYASAKI et al., 2003; MÉNDEZ; RIET-CORREA, 2007). Assim a alimentação com gramíneas ricas em oxalato é a principal causa de HNS, porém a utilização de rações desbalanceadas, com teores de cálcio aquém do recomendado, também pode causar a doença. Ospina et al. (2014) relataram um caso de HNS em uma égua alimentada com Pennisetum clandestinum. Deve-se considerar ainda que algumas situações são responsáveis pelo aumento da necessidade de cálcio, como exercício vigoroso, gestação e lactação, devendo-se nestes casos aumentar o fornecimento deste mineral (CARVALHO et al., 2011).

De acordo com Thomassian (2005) a deficiência de vitamina D em cavalos estabulados também é uma causa secundária de "cara inchada", uma vez que ela é necessária para que ocorra a absorção de cálcio pelo organismo.

Além de secundário à alimentação, o hiperparatireoidismo também pode ser secundário à insuficiência renal crônica, uma vez que ocorre diminuição da excreção de fósforo com consequente hiperfosfatemia e aumento na produção de paratormônio (WEISBRODE, 2001).

Hiperparatireoidismo primário, apesar de raro nos animais domésticos, também pode ser causa de osteodistrofia fibrosa, e está associado a tumores da glândula paratireóide (adenoma e carcinoma) ou hiperplasia idiopática bilateral (WEISBRODE, 2001).

\section{FISIOPATOGENIA}

O fósforo e o cálcio são os elementos minerais mais abundantes no organismo animal. O fósforo é classificado como um macroelemento mineral e encontra-se presente na maioria das moléculas orgânicas sob a forma de fosfato, um composto que contém fósforo e oxigênio (BONDI, 1989; TORIBIO, 2011). De acordo com Meyer (1995) um equino adulto possui em seu organismo cerca de $4 \mathrm{~kg}$ de fósforo, dos quais aproximadamente $80 \%$ encontram-se nos ossos e dentes, na forma de hidroxiapatita e fosfato de cálcio. Assim uma das principais funções do fósforo no organismo é proporcionar estabilidade mecânica, dureza e rigidez ao esqueleto (UNDERWOOD, 1981; TORIBIO, 2011). O restante do fósforo orgânico atua no metabolismo de gorduras e proteínas e compõe os ácidos nucléicos (DNA e RNA) (MACDOWELL, 1992). Do total de cálcio orgânico, 99\% encontram-se no esqueleto e uma pequena fração encontra-se como íons livres essenciais à condução nervosa, contração e relaxamento muscular, liberação hormonal 
e coagulação sanguínea, ligado a proteínas plasmáticas ou complexado a ácidos orgânicos ou inorgânicos (ANDRIGUETTO et al., 1993).

Nos ruminantes a excreção urinária de fósforo é baixa, ao contrário do que ocorre nos não ruminantes, sendo a eliminação pelas fezes o principal mecanismo de homeostase deste elemento (CHALLA; BRAITHWAITE, 1988).

A regulação hormonal da homeostase do cálcio e do fósforo é modulada principalmente pelos hormônios paratormônio (PTH), calcitonina e 1,25-dehidroxicolecalciferol, os quais atuam simultaneamente nos ossos, intestinos e rins. O PTH é responsável pela mobilização de cálcio dos ossos e diminuição da excreção, além de aumento na excreção urinária de fósforo. $\mathrm{O}$ aumento do fósforo plasmático estimula a secreção deste hormônio para que ocorra reabsorção de cálcio dos ossos a fim de manter a relação fisiológica normal de cálcio e fósforo (2:1) no sangue (SWARTZMAN et al., 1978).

Alterações na relação normal de cálcio e fósforo na corrente sanguínea são responsáveis pela hipersecreção de PTH e consequente hiperparatireoidismo, o qual se manifesta por osteodistrofia fibrosa, caracterizada pela substituição do tecido ósseo por tecido fibroso (CURCIO et al., 2010).

\section{SINAIS CLÍNICOS E DIAGNÓSTICO}

O principal sinal clínico do HNS, responsável inclusive pela denominação "doença da cara inchada", é o aumento, em geral bilateral e simétrico, dos ossos da face, decorrente à tumefação e amolecimento ósseo. Dispneia e dificuldade de deglutição podem estar presentes nos casos mais severos, devido à deformidade óssea (PUOLI-FILHO et al., 1999; MÉNDEZ; RIETCORREA, 2007 ). Segundo Smith (1993) trata-se de uma doença sistêmica na qual os ossos da cabeça são os mais gravemente acometidos, havendo espessamento dos ossos mandibular, palatino, zigomático e lacrimal. Segundo Jubb et al. (1993), em uma situação de excessiva mobilização óssea ocorre uma hierarquia de mobilização, sendo os ossos da mandíbula os primeiros a serem afetados, seguidos pelos ossos do crânio, costelas, vértebras e ossos longos. Alterações ósseas dos membros podem causar claudicação e incoordenação. Em alguns casos observa-se assimetria dos músculos dos membros, levando o animal a caminhar com passos curtos e apoiar-se nas pinças (PUOLI-FILHO et al., 1999; MÉNDEZ; RIET-CORREA, 2007). Segundo Radostits et al. (2002) os equinos podem apresentar queda do desempenho devido à dor, apresentando claudicação, exostose, deformação da coluna, fraturas e encurvamento dos membros. Nos estágios finais da doença observa-se emaciação e anemia intensas. 
Curcio et al. (2010) observou aumento de volume dos ossos da face e fisite distal do rádio em equinos da raça Mangalarga Marchador criados em pastagens de Panicum maximum cultivar Aruana. Ao exame radiográfico observaram-se áreas de redução da densidade óssea nas regiões afetadas. Ospina et al. (2014) também observaram abaulamento dos ossos da face de uma égua alimentada com Pennisetum clandestinum. Observaram ainda lacerações na boca associadas a espículas na superfície dos dentes molares e pré-molares, que encontravam-se enfraquecidos e podiam ser arrancados com facilidade.

Cruz et al. (2002), ao descreverem um caso de HNS em cabras de leite, observaram a presença de hipertrofia da mandíbula que encontrava-se dolorida à palpação. Alguns animais encontravam-se caquéticos e exames laboratoriais de duas cabras revelaram a diminuição dos níveis séricos de cálcio ionizado (0,80 e 0,91mmol/L). Bandarra et al. (2011) relataram um caso de HNS em sete cabritos com menos de um ano de idade. Os animais recebiam uma alimentação com relação de cálcio e fósforo de 1:6 e apresentavam espessamento da mandíbula e maxila, protusão da língua, dispnéia e dificuldade de preensão e mastigação.

O diagnóstico do HNS baseia-se principalmente na presença de sinais clínicos, em especial aumento de volume dos ossos da face. Exames bioquímicos podem revelar concentrações séricas de cálcio abaixo dos valores de referência e teor sérico de fósforo orgânico acima do normal. A atividade da enzima fosfatase alcalina pode estar aumentada. Exames radiográficos revelam opacidade óssea diminuída e à necropsia comumente observa-se ossos porosos (RADOSTITS et al., 2002).

\section{TRATAMENTO E PROFILAXIA}

De acordo com Thomassian (2005) o tratamento consiste basicamente na correção do desequilíbrio das concentrações de cálcio e fósforo e, segundo Radostits et al. (2002), mesmo as lesões mais graves podem desaparecer depois de algum tempo, após terapia adequada. Smith (1993) afirma que mesmo que ocorra alguma remodelamento a distorção facial costuma ser permanente.

A profilaxia do HNS é de extrema importância a fim de se evitar prejuízos econômicos com a doença. Para equinos rações com proporção de cálcio e fósforo de 1:1 são preventivas (RADOSTITS et al., 2002). Animais alimentados com dietas à base de cereais como milho, farelo de arroz ou trigo, que são ricos em fósforo e pobres em cálcio, e animais criados em pastagens ricas em oxalato devem ser suplementados com níveis adequados de cálcio (MÉNDEZ; RIET-CORREA, 2007). 


\section{CONSIDERAÇÕES FINAIS}

O HNS é uma doença que pode ser facilmente evitada e sua profilaxia é de extrema importância para se evitar prejuízos econômicos relacionados principalmente à diminuição do desempenho e do valor dos animais, quando se trata de equinos atletas e de animais de exposição. Em ruminantes a ocorrência natural da doença só foi descrita até o momento em cabras e os prejuízos econômicos nesta espécie estão relacionados à diminuição da produção principalmente devido à menor ingestão de alimentos (CRUZ et al., 2002; BANDARRA et al., 2011). Assim o fornecimento de alimentação de boa qualidade e com concentrações adequadas de cálcio e fósforo é uma prática indispensável no que tange o sucesso na criação de animais.

\section{REFERÊNCIAS}

ANDRIGUETTO, J.M.; PERLY, L.; MINARDI, I. Nutrição animal. São Paulo: Nobel, 1993. $395 \mathrm{p}$.

ASLANI, M.R. et al. Outbreak of osteodystrophia fibrosa in young goats. J. Vet. Med. A., v.48, n.7, p.385-389. 2001.

BANDARRA, P.M. et al. Nutritional fibrous osteodystrophy in goats. Pesq. Vet. Bras., v.31, n.10, p.875-878, 2011.

BONDI, A.A. Importancia nunritive de los minerals. In: . Nutrition Animal. Zarazoga: Acribia,1989.ca.10, p.175-187.

BRANDI, A.B.; FURTADO, C.E. Importância nutricional e metabólica da fibra na dieta de equinos. Revista Brasileira de Zootecnia, v.38, p.246-258, 2009.

CARVALHO, P.R. et al. Screening to prevent to carencial and metabolic disease and HPTNS of equids grazing forage grasses with unbalanced levels of mirerals, through the mineral profile and creatinine clearance ratio for $\mathrm{Ca}$ and $\mathrm{P}$ assessment. Pakistan Journal of nutrition, v.10, n.6, p.519-538, 2011.

CHALLA, J.; BRAITHWAITE, G.D. Phosphorus and calcium metabolism in growing calving with special emphasis on phosphorus homeostasis. Studies of the effects of changes in the dietary Pintake on P and Ca metabolism. Journal of Agricultural Science, v.110, n.3, p.573-58,1988.

CRUZ, L.C.; LIMA, M.S.; PELETEIRO, M.C. Osteodistrofia fibrosa em cabras de leite. Revista Portuguesa de Ciências Veterinárias, v.534, n.97, p.147-150, 2002.

CURCIO, B.R. et al. Osteodistrofia fibrosa em equinos criados em pastagens de Panicum maximum cultivar Aruana: relato de casos. Arq. Bras. Med. Vet. Zootec., v.62, n.1, p.37-41, 2010 . 
HINCHCLIFF, K.W.; GEOR, R.J. Integrative physiology of exercise. In: HINCHCLIFF, K. et al. Equine Sports Medicine and Surgery. Philadelphia: Saunders, 2004. p.3-8.

JUBB, K.V.F. et al. Pathology of domestic animals. 4.ed. San Diego: Academic Press, 1993. $181 \mathrm{p}$.

LEITE, J.E.B. et al. Aspectos radiográficos da mandíbula e crista interdentária de bovinos induzidos ao hiperparatiroidismo secundário nutricional. R. Bras. Ci. Vet., v.11, n.1/2, p.16-20.

MACDOWELL, L.R. Mineral in animal and human nutrition. San Diego: Academic Press, 1992. 524p.

MÉNDEZ, M.C.; RIET-CORREA, F. Osteodistrofia fibrosa. In: RIET-CORREA, F. et al. Doenças de ruminantes e equinos. 3.ed. São Paulo: Varela, 2007, cap.1, v.2, p.289-293.

MEYER, H. Alimentação de cavalos. 2.ed. São Paulo: Varela, 1995. p.303.

MIYASAKI, S.; YAMANAKA, N.; GURUGE, K.S. Simple capillary electrophoretic determination of soluble oxalate and nitrate in forage grasses. J. Vet. Diagn. Invest., v.15, p.480483, 2003.

NATIONAL RESEARCH COUNCIL. Nutrient requirements for horses. 5 ed. revisada. Washington: National Academy of Sciences, 1989. 100p.

OSPINA, J.C.; DONCEL, B.; GARCÍA, N.V. Maxillofacial Fibrous Osteodystrophy in Equine: Case Report. Braz. J. Vet. Pathol., n.7, v.2, p.100-105, 2014.

PAGAN, J.D. Forages for horses: More than just filler. In: Advances in equine nutrition. Nottingham: Nottingham University, 1998. p.13-28.

PUOLI-FILHO, J.N.P. et al. Suplementação mineral e mobilização de cálcio nos ossos de equinos em pastagens de Brachiaria humidicola. Pesq. Agrop. Bras., v.34, p.873-878, 1999.

RADOSTITS, O.M.et al. Clínica veterinária. Um tratado de doenças dos bovinos, ovinos, suínos, caprinos e equinos. 9 ed. Rio de Janeiro: Guanabara Koogan, 2002.

SMITH, B.P. Tratado de medicina interna de grandes animais. São Paulo: Manole, 1993. v.2. p.1310-1311.

SWARTZMAN, M.S. et al. Inhibition of calcium absorption in ponies fed diets containing oxalic acid. American Journal of Veterinary Research., v.39, n.10, p.1621-1623, 1978.

THOMASSIAN, A. Enfermidades de Cavalos. 4.ed. Botucatu: Varela, 2005. 573p.

TORIBIO RE. Disorders of calcium and phosphate metabolism in horses. Vet. Clin. North. Am. Equine Pract., v.27, p.129-47, 2011.

UNDERWOOD, E.J. The mineral nutrition of livestock. 2.ed. Farham Royal: Comm. Agric. Bureaux, 1981.180p.

WEISBRODE, S.E.; DOIGE, C.E. Bone and joints. In: McGavin, M.D.; Carlton, W.W.; Zachary, J.F. Thomson's special veterinary pathology. St. Louis: Mosby, 2001. p.499-536. 
